\title{
Numerical modeling of fluid flow, heat, and mass transfer for similar and dissimilar laser welding of Ti-6AI-4V and Inconel 718
}

\author{
Amir Hossein Faraji ${ }^{1,2} \cdot$ Carmine Maletta $^{1}$ (1) $\cdot$ Giuseppe Barbieri $^{3} \cdot$ Francesco Cognini $^{3} \cdot$ Luigi Bruno $^{1}$
}

Received: 23 November 2020 / Accepted: 5 March 2021 / Published online: 23 March 2021

(C) The Author(s) 2021

\begin{abstract}
Most of the researches published on the numerical modeling of laser welding are looking at similar welding, mainly due to the difficulty of simulating the mixing phenomenon that occurs in dissimilar welding. Furthermore, numerical modeling of dissimilar laser welding of titanium and nickel alloys has been rarely reported in the literature. In this study, a 3D finite volume numerical model is proposed to simulate fluid flow, heat, and mass transfer for similar and dissimilar laser welding of Ti-6Al-4V and Inconel 718. The laser source was simulated by volumetric heat distribution, which considers the effects of keyhole and heat transfer on the workpiece. The heat source parameters were calibrated through preliminary experiments, by comparing the simulated and experimental weld pool shapes and dimensions. The model was used to simulate both homogenous and dissimilar laser weldings of Ti-6Al-4V and Inconel 718, and a systematic comparison was carried out through a number of selected experiments. The effects of three distinct levels of laser power $(1.25 \mathrm{~kW}, 1.5 \mathrm{~kW}, 2.5 \mathrm{~kW})$ on temperature distribution and velocity field in the welds pool were analyzed. Results highlighted the effects of Marangoni forces in the weld pool formation. Furthermore, in order to analyze the mass transfer phenomenon in dissimilar welding, species transfer equations were considered, demonstrating the important role played by the mass mixture in the weld pool formation. Finally, a high level of agreement between simulations and experiments - in terms of weld pool shape and dimensions - was observed in all cases analyzed. This proves the ability of the proposed numerical model to properly simulate both the similar and dissimilar welding of Ti-6Al-4V and Inconel 718 alloys.
\end{abstract}

Keywords Numerical modeling $\cdot$ Heat transfer and fluid flow $\cdot$ Weld pool $\cdot$ Laser welding $\cdot$ Ti-6Al-4V $\cdot$ Inconel 718

\begin{tabular}{ll}
\multicolumn{2}{l}{ Nomenclature } \\
$t$ & Time \\
$\rho$ & Density \\
$x, y, z$ & Cartesian coordinates \\
$v_{x}, v_{y}, v_{z}$ & Components of the velocity vector \\
$x_{0}, y_{0}$ & Laser location in the $x y$ plane \\
$\mu$ & Viscosity \\
$p$ & Pressure \\
$T$ & Temperature
\end{tabular}

Carmine Maletta

carmine.maletta@unical.it

1 Department of Mechanical, Energy and Management Engineering, University of Calabria, Via Bucci 44C, 87036 Rende, CS, Italy

2 School of Metallurgy and Materials Engineering, Iran University of Science and Technology, Tehran, Iran

3 Department for Sustainability, Research Center of Casaccia, ENEA, Santa Maria di Galeria, 00123 Rome, Italy
$T_{0} \quad$ Reference temperature

$g \quad$ Gravity acceleration

$H \quad$ Total enthalpy

$K \quad$ Effective thermal conductivity

$c_{\mathrm{L}} \quad$ Specific heat of liquid

$c_{\mathrm{S}} \quad$ Specific heat of solid

$\kappa_{\mathrm{L}} \quad$ Thermal conductivity of liquid

$\kappa_{\mathrm{S}} \quad$ Thermal conductivity of solid

$T_{\mathrm{L}} \quad$ Liquidus temperature

$T_{\mathrm{S}} \quad$ Solidus temperature

$L \quad$ Latent heat of fusion

$f_{\mathrm{L}} \quad$ Liquid fraction

$M \quad$ Mushy zone morphology constant

$\gamma \quad$ Surface tension

$q_{\mathrm{C}} \quad$ Convective heat

$q_{\mathrm{R}} \quad$ Radiation heat

$w \quad$ Mass fraction of species

$D \quad$ Diffusion coefficient

Xup Upper laser energy contribution 


$\begin{array}{ll}q_{\mathrm{L}} & \text { Volumetric laser heat input } \\ \eta_{\mathrm{L}} & \text { Laser efficiency } \\ L_{\mathrm{D}} & \text { Laser distribution parameter } \\ P & \text { Laser power } \\ R_{\mathrm{e}}, R_{\mathrm{i}} & \begin{array}{l}\text { Maximum and minimum radius of the conical por- } \\ \text { tion of the keyhole }\end{array} \\ R(z) \quad \begin{array}{l}\text { Radius at the generic position of the conical por- } \\ \text { tion of the keyhole }\end{array} \\ z_{\mathrm{i}} & \begin{array}{l}\text { Height of the conical portion of the keyhole } \\ z_{\mathrm{KH}}\end{array} \\ P_{\mathrm{e}} & \text { Keyhole depth } \\ V_{\max } & \text { Peclet number } \\ L_{\mathrm{C}} & \text { Maximum fluid velocity } \\ \end{array}$

\section{Introduction}

The laser welding process is widely used in many industries, including automotive, oil and gas, shipbuilding, and aerospace industries, due to its economic and technological advantages $[1,2]$. Unfortunately, the welding of advanced alloys, such as those which are titanium-based, is a rather complex task given their high chemical activity and the microstructural changes that occur in the fused and heat-affected zone. The problem is further complicated in cases dealing with dissimilar joints, where an intermetallic compound formation results in poor mechanical properties.

Recently, titanium alloys have been commonly used in high-performance applications across several fields (e.g., aerospace, automotive) because of their high level of strength, good corrosion, and creep resistance [3, 4]. In addition, nickel alloys have been increasingly used in similar fields due to their excellent mechanical properties at high temperatures. Therefore, the laser welding of titanium and nickel alloys has been of growing interest for industrial applications, most notably in the aerospace industry, where it can be used to manufacture parts destined for high-temperature regions of the engine and turbine [5, 6]. Recently, the dissimilar welding process has attracted more attention in light of its economic benefits and design flexibility, offering the possibility of applying optimal material to critical locations [7]. Nevertheless, the use of dissimilar welding in place of similar welding requires challenging concerns that arise for two important reasons: the different thermo-physical properties of the base materials can affect heat transfer in the weld pool; the mixing process in the weld pool changes its composition, with consequences visible in both the heat transfer and fluid flow [8].

Geometrical weld parameters (i.e., weld depth, weld width, the overall shape of weld puddle) together with the microstructural weld characteristics (i.e., cooling rate, residual stresses) affect weld quality and properties. The weld pool geometry and cooling rate is determined by heat and mass transfer and fluid flow in the weld pool [9-11]. In recent decades, several numerical models have been developed to simulate heat transfer, fluid flow, and weld shape in the weld pool $[10,12,13]$. Moreover, several studies proposed analytical models to predict the temperature distribution in the welding when a laser heat source was used [14-16]. At present, most of the research published on the numerical modeling of laser welding are looking at similar welding, mainly due to the difficulty of simulating the mixing phenomenon that occurs in dissimilar welding, significantly affecting the physical and thermal properties of the joint $[17,18]$.

Shaibu et al. [19] analyzed the thermal profile of the weld pool of a dissimilar laser welding with copper and 304 stainless steels. However, they did not model fluid flow and material mixing in the weld pool. Phanikumar et al. [20] developed a three-dimensional transient model to simulate the mixing of molten metal in laser welding of $\mathrm{Cu}-\mathrm{Ni}$ dissimilar joints. Rai et al. [21] studied heat transfer and fluid flow in the dissimilar welding of Ti-6Al-4V alloy and $\mathrm{Cr}-6 \mathrm{Ni}-9 \mathrm{Mn}$ steel, but they did not consider the effect of the materials' mixture in the weld pool. Hu et al. [22] used a three-dimensional heat and mass transfer model to simulate the welding process employing equations of mass, momentum, energy conservation, and solute transport in the laser dissimilar welding of stainless steel and nickel. Their results showed that both heat and mass transport are significantly influenced by convection during the laser spot welding process. Métais et al. [23] investigated the alloy element mixing in the weld pool using a $3 \mathrm{D}$ multiphysical model in the laser welding of two different steels. They found that the tensile behavior of the welds is related to levels of Mn and C dilutions. Esfahani et al. [24] developed a 3D multiphase computational fluid model to investigate the melted pool fluid dynamics and alloy composition in a dissimilar laser welding of low carbon steel and stainless steel. Xue et al. [7] studied weld pool characterization in a dissimilar laser welding of a $\mathrm{Cu}-\mathrm{Al}$ lap joint using a 3D finite volume model. They calculated the weld pool temperature distribution, velocity field, and alloying distribution in the weld pool. However, in most of these literature studies only the conduction laser welding was simulated and keyhole mode mechanism was not considered. It means that they used a radial symmetric Gaussian heat distribution at top surface to model the laser heat source. On the other hand, the model described in the present manuscript proposes a keyhole mode laser welding with a volumetric heat source, adjusted according to laser characteristics and weld material.

In the present state of the art, numerical modeling of dissimilar laser welding of titanium and nickel alloys has not been widely reported in the literature. In this study, we developed a three-dimensional numerical model to simulate the laser welding of titanium and nickel alloys butt welding. This model is intended to analyze temperature history, fluid 
velocity profile, the melted pool mixing pattern, and weld pool shape during three cases of laser welding including a bead on plate penetration test on Ti-6Al-4V, a bead on plate penetration test on Inconel 718, and a dissimilar butt joint welding of Ti-6Al-4V to Inconel 718. To calibrate and validate the numerical models, several experiments were carried out. First, we developed two separated models for similar laser welding of Ti-6Al-4V and Inconel 718 to calibrate the heat source model, comparing the calculated and experimental weld shapes. Afterward, a model was developed for the dissimilar welding of Ti-6Al-4V to Inconel 718. The simulated and experimental weld shapes were compared to validate the model. Finally, to investigate the effect of material mixing on the weld shape, two conditions were considered in the case of a dissimilar welding, without and with implementing the species equation into the model.

It is worth mentioning that to reach full penetration in different combinations of welding parameters, lots of experiments are needed. Hence, once properly calibrated and optimized, the numerical modeling can reduce significantly the required experiments, with a consequent saving of processing time and production cost. Moreover, numerical modeling can provide a better understanding of the process parameters' impact on the welding mechanical and microstructural properties.

\section{Numerical model}

In this paper, a steady-state three-dimensional numerical model with a coordinate system moving with the heat source was developed to simulate the heat transfer, mass transfer, and fluid flow occurring during the laser welding of a Ti-6Al-4V and Inconel 718 butt welding. The aim of these simulations was to investigate the temperature history, fluid velocity profile, melted pool mixing pattern, and weld pool shape in the following three cases of laser welding:

- Case study \#1: bead on plate penetration test on Ti-6Al-4V

Fig. 1 Schematic diagram of the computational domain used for the numerical model
- Case study \#2: bead on plate penetration test on Inconel 718

- Case study \#3: dissimilar butt joint welding of Ti-6Al-4V to Inconel 718

A schematic diagram of the computational domain used for the numerical modeling is shown in Fig. 1, with a volume of $30 \mathrm{~mm} \times 30 \mathrm{~mm} \times 3 \mathrm{~mm}$. The length and width of the domain were chosen as sidelong boundaries are far enough from the melted pool in order to make the boundary effects negligible.

The mesh is uniform along the thickness ( $z$ direction), whereas it is non-uniform along the width ( $y$ direction) and length ( $x$ direction). The mesh size and number of elements were chosen after performing some mesh convergence tests. A finer grid was modeled in the area where the heat source hits the material, with the smallest element (directly below the heat source) consisting of a cube, the side of which measures 0.1 $\mathrm{mm}$. The total number of elements is approximately 900,000. The laser source was applied to the center of the computational domain, sufficiently far from the four edges $(15 \mathrm{~mm})$, in order to ensure negligible border effects.

With the aim of reducing the computational time without significantly affecting the accuracy of the solution, the following simplifying assumptions were made:

- Fluid flow in the molten pool is Newtonian and incompressible [25-27].

- The weld pool surface is assumed to be flat.

- Although keyhole dynamic is neglected to simplify the numerical model and reduce computational time, to take into account the laser energy penetrated to the workpiece through the keyhole, a volumetric heat source model is used for the simulation of the keyhole effect on the formation of the weld pool [9, 10, 28-33].

- The physical and thermal properties of weld metal, such as the specific heat $(c)$ and thermal conductivity (K), are assumed to be different for liquid and solid phases, as reported in Table 1 [21, 34-37], which lists the set of physical properties used in the simulations.

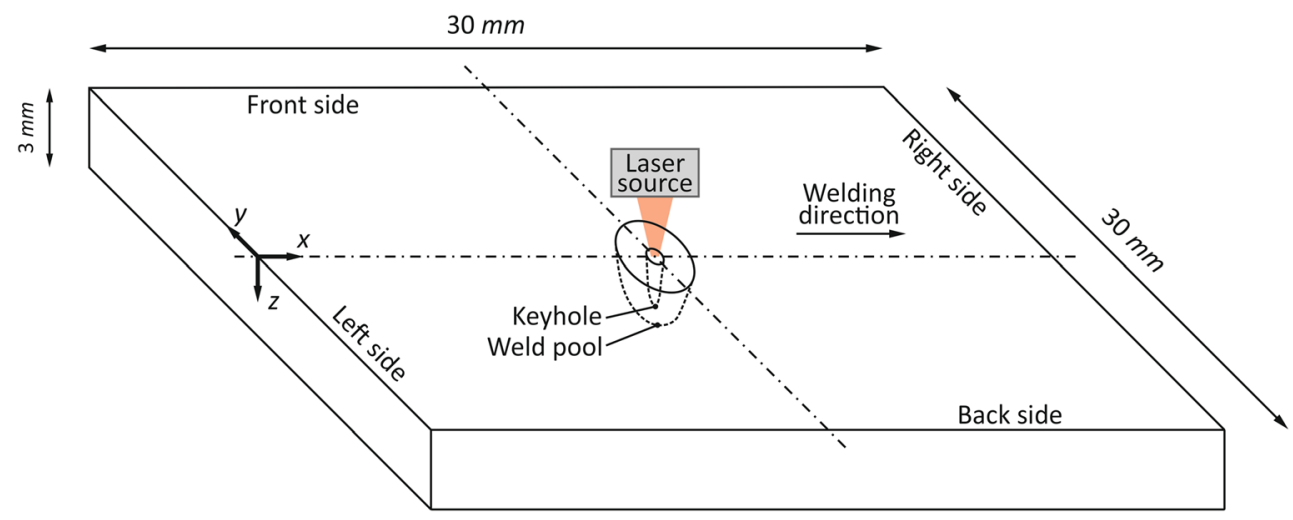


Table 1 Value of the physical properties used in the simulations

\begin{tabular}{llll}
\hline Property & $\begin{array}{l}\text { Ti-6Al- } \\
4 \mathrm{~V}\end{array}$ & Inconel 718 & Unit \\
\hline$\rho$ & 4430 & 8190 & $\mathrm{~kg} \mathrm{~m}^{-3}$ \\
$c_{\mathrm{L}}$ & 730 & 725 & $\mathrm{~J} \mathrm{~kg}^{-1} \mathrm{~K}^{-1}$ \\
$c_{\mathrm{S}}$ & 670 & 577 & $\mathrm{~J} \mathrm{~kg}^{-1} \mathrm{~K}^{-1}$ \\
$\kappa_{\mathrm{L}}$ & 24 & 29 & $\mathrm{~W} \mathrm{~m}^{-1} \mathrm{~K}^{-1}$ \\
$\kappa_{\mathrm{S}}$ & 21 & 27 & $\mathrm{~W} \mathrm{~m}^{-1} \mathrm{~K}^{-1}$ \\
$D$ & $10^{-6}$ & $10^{-6}$ & $\mathrm{~m}^{2} \mathrm{~s}^{-1}$ \\
$\mu$ & 0.03 & 0.03 & $\mathrm{~kg} \mathrm{~m}^{-1} \mathrm{~s} \mathrm{~s}^{-1}$ \\
$T_{\mathrm{L}}$ & 1928 & 1608 & $\mathrm{~K}$ \\
$T_{\mathrm{S}}$ & 1878 & 1523 & $\mathrm{~K}$ \\
$L$ & 418.8 & 272 & $\mathrm{~kJ} \mathrm{~kg} 1$ \\
\hline
\end{tabular}

- In the case of dissimilar welding, the physical and thermal properties of weld pool metal depend on the composition and are estimated by the mass-weighted mixing law [17, $18,20,22]$.

- A simple turbulence model based on Prandtl's mixing length hypothesis, presented in previous studies $[9,10$, 31-33], is used to estimate the turbulent viscosity.

- Total enthalpy $H$ is defined as the sum of sensible heat and latent heat and is defined as $f_{1} L$.

With the above assumptions, conservation equations of continuity, momentum, energy, and mass fraction are numerically satisfied in the simulations in order to calculate temperature history, velocity fields, and species mixing pattern in the weld. All these equations are reported in Table 2, with all symbols defined in the nomenclature sections.

The constant $M$, the mushy zone morphology constant, was set equal to 160,000 , while $B$ is a number sufficiently small to avoid division by zero and set to the default value by the simulation software [10, 31, 32].

To consider the melting process during welding, an appropriate melting and solidification model was embedded, together with heat transfer and fluid flow models. Melting and solidification were modeled with an enthalpy-porosity formulation based on liquidus and solidus temperatures, explained in detail in previous publications $[9,10,31-33]$.

The standard SIMPLE (Semi-Implicit Method for Pressure-Linked Equation) algorithm [38] was used for pressure-velocity coupling, and the upwind scheme was used for discretization of the convection terms in the governing equations. To meet convergence requirements, the calculations were executed by applying the appropriate underrelaxation factor. In the present study, the convergence criteria were set to $10^{-3}$ for the momentum equations and to $10^{-6}$ all the other equations.

The boundary conditions imposed in the numerical model are listed in Table 3. At the top and bottom surface, Marangoni stress due to temperature gradient of surface tension coefficient was applied for momentum equations, and convective and radiation heat losses were considered for the energy equation. On the other boundary surfaces, the temperature was set

Table 2 Equations numerically solved by the simulations

Continuity equation

$$
\frac{\partial \rho}{\partial t}+\frac{\partial}{\partial x}\left(\rho v_{x}\right)+\frac{\partial}{\partial y}\left(\rho v_{y}\right)+\frac{\partial}{\partial z}\left(\rho v_{z}\right)=0
$$

Momentum equations

Energy equation

$$
\left\{\begin{array}{c}
\frac{\partial}{\partial t}\left(\rho v_{x}\right)+\frac{\partial}{\partial x}\left(\rho v_{x}^{2}\right)+\frac{\partial}{\partial y}\left(\rho v_{x} v_{y}\right)+\frac{\partial}{\partial z}\left(\rho v_{x} v_{z}\right)= \\
=\frac{\partial}{\partial x}\left(\mu \frac{\partial v_{x}}{\partial x}-p\right)+\frac{\partial}{\partial y}\left(\mu \frac{\partial v_{x}}{\partial y}\right)+\frac{\partial}{\partial z}\left(\mu \frac{\partial v_{x}}{\partial z}\right)-M \frac{\left(1-f_{\mathrm{L}}\right)^{2}}{f_{\mathrm{L}}^{3}+B} v_{x} \\
\frac{\partial}{\partial t}\left(\rho v_{y}\right)+\frac{\partial}{\partial x}\left(\rho v_{x} v_{y}\right)+\frac{\partial}{\partial y}\left(\rho v_{y}^{2}\right)+\frac{\partial}{\partial z}\left(\rho v_{y} v_{z}\right)= \\
=\frac{\partial}{\partial x}\left(\mu \frac{\partial v_{y}}{\partial x}\right)+\frac{\partial}{\partial y}\left(\mu \frac{\partial v_{y}}{\partial y}-p\right)+\frac{\partial}{\partial z}\left(\mu \frac{\partial v_{y}}{\partial z}\right)-M \frac{\left(1-f_{\mathrm{L}}\right)^{2}}{f_{\mathrm{L}}^{3}+B} v_{y} \\
\frac{\partial}{\partial t}\left(\rho v_{z}\right)+\frac{\partial}{\partial x}\left(\rho v_{x} v_{z}\right)+\frac{\partial}{\partial y}\left(\rho v_{y} v_{z}\right)+\frac{\partial}{\partial z}\left(\rho v_{z}^{2}\right)= \\
=\frac{\partial}{\partial x}\left(\mu \frac{\partial v_{z}}{\partial x}\right)+\frac{\partial}{\partial y}\left(\mu \frac{\partial v_{z}}{\partial y}\right)+\frac{\partial}{\partial z}\left(\mu \frac{\partial v_{z}}{\partial z}-p\right)-M \frac{\left(1-f_{\mathrm{L}}\right)^{2}}{f_{\mathrm{L}}^{3}+B} v_{y}+\rho g\left(T-T_{0}\right) \\
\frac{\partial}{\partial t}(\rho H)+\frac{\partial}{\partial x}\left(\rho v_{x} H\right)+\frac{\partial}{\partial y}\left(\rho v_{y} H\right)+\frac{\partial}{\partial z}\left(\rho v_{z} H\right)= \\
=\frac{\partial}{\partial x}\left(K \frac{\partial T}{\partial x}\right)+\frac{\partial}{\partial y}\left(K \frac{\partial T}{\partial y}\right)+\frac{\partial}{\partial z}\left(K \frac{\partial T}{\partial z}\right)+q_{\mathrm{laser}} \\
\frac{\partial}{\partial t}(\rho w)+\frac{\partial}{\partial x}\left(\rho v_{x} w\right)+\frac{\partial}{\partial y}\left(\rho v_{y} w\right)+\frac{\partial}{\partial z}\left(\rho v_{z} w\right)= \\
=\frac{\partial}{\partial x}\left(\rho D \frac{\partial w}{\partial x}\right)+\frac{\partial}{\partial y}\left(\rho D \frac{\partial w}{\partial y}\right)+\frac{\partial}{\partial z}\left(\rho D \frac{\partial w}{\partial z}\right)
\end{array}\right.
$$


Table 3 Boundary conditions for velocity components, temperature, and mass fraction imposed in the numerical simulations

\begin{tabular}{|c|c|c|c|c|c|}
\hline Surface & $v_{x}$ & $v_{y}$ & $v_{z}$ & $T$ & $w$ \\
\hline Top & $\mu \frac{\partial v_{x}}{\partial z}=f_{\mathrm{L}} \frac{\partial \gamma}{\partial T} \frac{\partial T}{\partial x}$ & $\mu \frac{\partial v_{y}}{\partial z}=f_{\mathrm{L}} \frac{\partial \gamma}{\partial T} \frac{\partial T}{\partial y}$ & 0 & $q=q_{\mathrm{C}}+q_{\mathrm{R}}$ & $\frac{\partial w}{\partial z}=0$ \\
\hline Bottom & $\mu \frac{\partial v_{x}}{\partial z}=f_{\mathrm{L}} \frac{\partial \gamma}{\partial T} \frac{\partial T}{\partial x}$ & $\mu \frac{\partial v_{y}}{\partial z}=f_{\mathrm{L}} \frac{\partial \gamma}{\partial T} \frac{\partial T}{\partial y}$ & 0 & $q=q_{\mathrm{C}}+q_{\mathrm{R}}$ & $\frac{\partial w}{\partial z}=0$ \\
\hline Front & 0 & 0 & 0 & $300 K$ & $\frac{\partial w}{\partial y}=0$ \\
\hline Back & 0 & 0 & 0 & $300 K$ & $\frac{\partial w}{\partial y}=0$ \\
\hline Left & 0 & 0 & 0 & $300 K$ & $\frac{\partial w}{\partial x}=0$ \\
\hline Right & 0 & 0 & 0 & $300 K$ & $\frac{\partial w}{\partial x}=0$ \\
\hline
\end{tabular}

to room temperature, and velocity components were set to zero. For the mass fraction equation, a zero diffusive flux was imposed at all boundary surfaces.

\section{Laser heat source model}

In a laser welding, most of the heat is concentrated in a small volume, creating a cavity containing ionized vapors, referred to as keyhole $[25,39,40]$. The heat produced by the laser source flows below the surface of the workpiece, and, by way of several physical mechanisms, it crosses the walls of the keyhole $[25,29]$. Based on the reversed-bugle shape of the laser-created keyhole [40], a combined effective heat source model was applied in this study. It consists of a conical volumetric heat source in the upper part and a cylindrical volumetric heat source in the lower part, as schematically depicted in Fig. 2, which shows the section in the $x z$ plane of the aforementioned keyhole.
With reference to Fig. 2, the laser heat source $q_{\mathrm{L}}$ was modeled by the following equations:

$q_{\mathrm{L}}=\left\{\begin{array}{ll}\frac{\chi_{\mathrm{up}} \eta_{\mathrm{L}} L_{\mathrm{D}}^{2} P}{\pi z_{i}\left(1-e^{-3}\right)\left(R_{i}^{2}+R_{i} R_{e}+R_{e}^{2}\right)} \exp \left(-\frac{L_{\mathrm{D}}\left[\left(x-x_{0}\right)^{2}+\left(y-y_{0}\right)^{2}\right]}{R(z)^{2}}\right) & \text { for } 0 \leq z \leq z_{i} \\ \frac{\left(1-\chi_{\mathrm{up}}\right) \eta_{\mathrm{L}} P}{\pi R_{i}^{2}\left(z_{\mathrm{KH}}-z_{i}\right)} & \text { for } z_{i} \leq z \leq z_{\mathrm{KH}}\end{array}\right.$.

In the specific case of the present study, the laser source was applied at the center of the workpiece $\left(x_{0}=15 \mathrm{~mm}, y_{0}=\right.$ 0 ). The distance $R(\mathrm{z})$, according to assumptions made about the geometry of the keyhole, varies linearly, between $R_{\mathrm{e}}$ at $z=$ 0 and $R_{\mathrm{i}}$ at $z=z_{\mathrm{i}}$.

One of the most challenging aspects of modeling the welding process is the tuning of heat source parameters. In this study, laser heat source parameters were calibrated by comparing the calculated and experimental weld shape at the laser powers of $1.25 \mathrm{~kW}$ and $2.5 \mathrm{~kW}$. In particular, the laser
Fig. 2 Schematic diagram of the section of the keyhole in the $x z$ plane

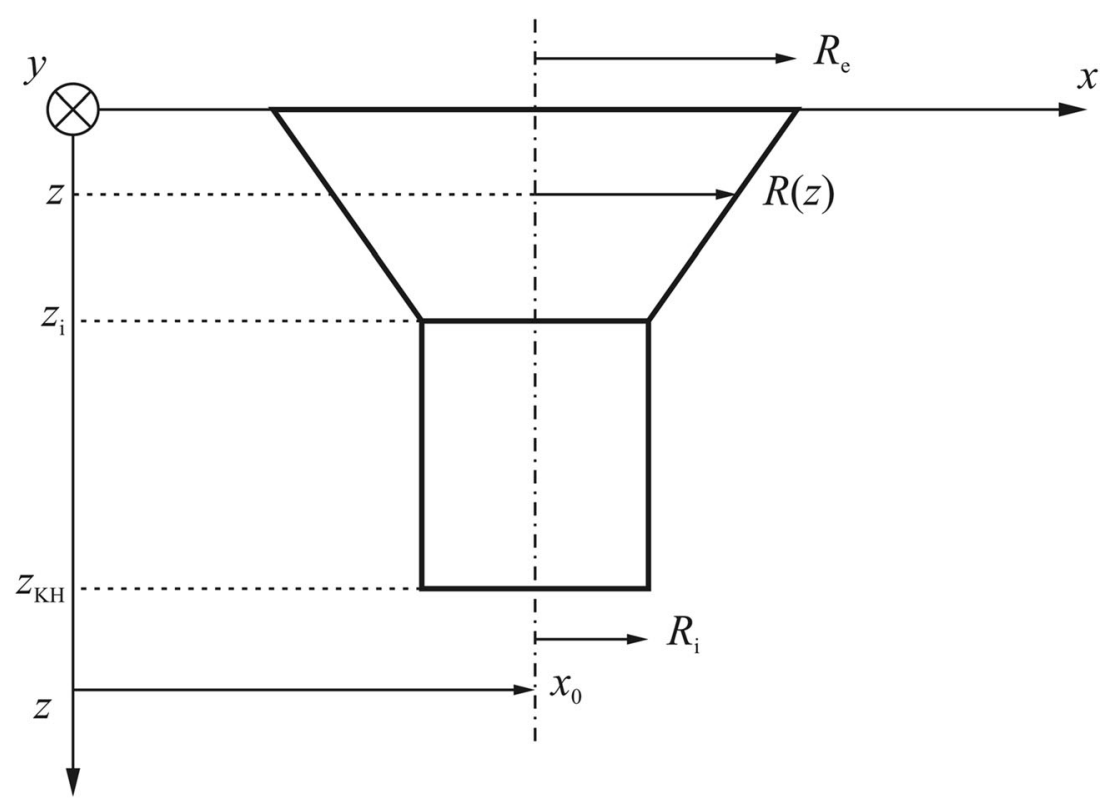


efficiency coefficient was chosen by trial and error methods for the two aforementioned laser powers, for both similar laser weldings of Ti-6Al-4V and Inconel 718 alloys. By varying the laser efficiency in the model, the weld puddle geometry does not change significantly, whereas only the change of the size of the weld puddle was observed. Hence, we calibrated other heat source parameters to obtain the overall shape of weld puddle firstly, and then the laser efficiency was calibrated to attain the experimental size of weld puddle.

The laser heat source parameters for the laser welding of Ti-6Al-4V and Inconel 718 alloys are reported in Table 4. They were evaluated by the aforementioned calibration procedure of the numerical models, with the exception of $L_{\mathrm{D}}$, whose value was chosen according to literature references $[10,31,32]$. It is notable that the $z_{\mathrm{KH}}$ is calculated as a function of laser power $P$, that $z_{\mathrm{i}}$ is a fraction of $z_{\mathrm{KH}}$, and that the other heat source parameters are constant. According to these assumptions, the only variable necessary to model the laser heat source is the laser power. After establishing the heat source parameters, the weld pool shape and dimensions were validated by comparing the numerical and experimental data for the laser power of $1.5 \mathrm{~kW}$.

After calibrating the heat source model for similar laser welding of Ti-6Al-4V and Inconel 718 alloys, the heat source parameters to simulate the dissimilar welding were chosen for each side separately, based on the calibrated parameters of the similar welding models.

\section{Experimental procedure}

The equipment used to execute the bead tests and the butt weldings is an IPG Photonics fiber laser source model YLS4000, whose main technical specifications are summarized in Table 5. The beam was experimentally characterized by PRIMES Focus monitor FM 120, and the measured specifications are shown in Fig. 3. The difference observed between the standard and measured specifications is due to the additional optical path traveled by the laser beam between the exit of the

Table 4 Laser heat source parameters used in the numerical simulations

\begin{tabular}{lll}
\hline Laser parameter & Ti-6Al-4V & Inconel 718 \\
\hline$L_{\mathrm{D}}$ & 2.00 & 2.00 \\
$\eta_{\mathrm{L}}$ & 0.90 & 0.65 \\
$\chi_{\text {up }}$ & 0.65 & 0.60 \\
$R_{\mathrm{e}}[\mathrm{mm}]$ & 1.20 & 0.60 \\
$R_{\mathrm{i}}[\mathrm{mm}]$ & 0.35 & 0.30 \\
$z_{\mathrm{KH}}[\mathrm{mm}]$ & $0.8 P+1$ & $0.8 P+1$ \\
$z_{\mathrm{i}}[\mathrm{mm}]$ & $0.4 z_{\mathrm{KH}}$ & $0.3 z_{\mathrm{KH}}$ \\
\hline
\end{tabular}

To obtain $z_{\mathrm{KH}}$ in $\mathrm{mm}, P$ has to be in $k W$
Table 5 Standard technical specifications of the laser source

\begin{tabular}{ll}
\hline Maximum nominal power & $4.2 \mathrm{~kW}$ \\
\hline Wavelength & $1060 \mathrm{~nm}$ \\
Fiber transport diameter & $100 \mu \mathrm{m}$ \\
Focal length of wobbling focusing & $250 \mathrm{~mm}$ \\
Divergence & $50 \mathrm{mrad}$ \\
Beam product parameter & $3 \mathrm{~mm} \mathrm{mrad}$ \\
\hline
\end{tabular}

laser source's head (where the standard specifications are measured by the seller) and the working spot (where the laser beam was characterized by the authors and the weld pool is made). In fact, along the optical path, several optical elements are met (i.e., transmission fiber, collimator, wobbling mirrors, focusing lens), which induced some modifications due to their unavoidable imperfections.

In particular, Fig. 3a shows how the beam was reconstructed around the waist area, by 30 sections equispaced on a length of $40 \mathrm{~mm}$. Each section was characterized by a square matrix of $64 \times 64$ pixels, the dimension of which was automatically chosen according to the light energy distribution. Figure $3 \mathrm{~b}$ shows energy distribution at the section closest to the waist area and the most relevant parameters of the laser beam, obtained by applying the 2 nd moment algorithm according to ISO standard 11166-1:2005. The red dashed line represents the diameter of the beam waist, at $0.253 \mathrm{~mm}$, evaluated by the aforementioned algorithm. The parameters obtained by this optical characterization resulted to be consistent with the assumptions made in the numerical simulations. In fact, as expected the measured beam waist was smaller than the diameter of the laser beam adopted in the solids, and the Rayleigh length - which quantifies the divergence of the beam-resulted to be significantly higher than the thickness of the welded plates. In Fig. 4, a picture of the welding set-up shows the red pilot laser and the clamping system used to fix the specimen.

The wobbling focusing head moves the focal point with two galvanometric mirrors (frequency up to $1 \mathrm{kHz}$, displacement up to $4 \mathrm{~mm}$ ). Forward movement is given by a digital positioner (builder: Pegaso Sistemi Srl) with the $x, y$, and $z$ strokes equal to $550 \mathrm{~mm}, 550 \mathrm{~mm}$, and $300 \mathrm{~mm}$, respectively. The maximum speed attainable by the controller is $0.167 \mathrm{~m} / \mathrm{s}$.

The bead tests and the butt weldings were made with two 3mm thick plates of Ti-6Al-4V and Inconel 718, whose compositions provided by the material sellers are reported in Table 6 . The welding speed was set to $60 \mathrm{~mm} / \mathrm{s}$. The focal point of the laser beam lies $1 \mathrm{~mm}$ below the surface of the workpiece. In this operating condition, the spot diameter of the laser beam on the top surface of the workpiece was approximately $0.25 \mathrm{~mm}$. Argon was applied as a shielding gas. The bead on plate penetration tests introduced at the beginning 


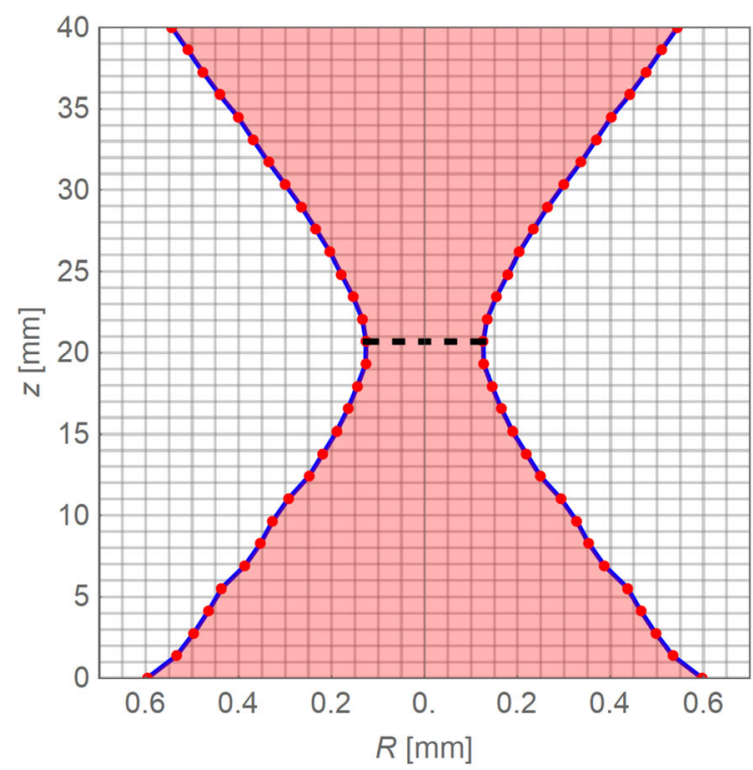

a

$\begin{array}{ll}\text { Diameter of beam waist } & 0.253 \mathrm{~mm} \\ \text { Waist } z \text {-position } & 20.480 \mathrm{~mm} \\ \text { Rayleigh length } & 4.597 \mathrm{~mm} \\ \text { Beam propagation factor } & 0.097 \\ \text { Diffraction index } & 10.3 \\ \text { Beam parameter } & 3.468 \mathrm{~mm} \mathrm{mrad} \\ \text { Divergence } & 54.927 \mathrm{mrad}\end{array}$

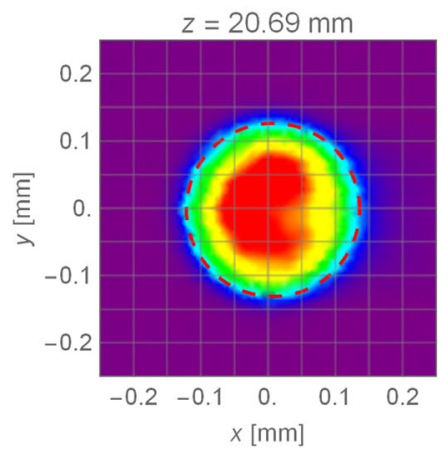

b

Fig. 3 Report of the experimental characterization of the laser beam: a shape of the beam reconstructed by 30 sections equispaced on a length of 40 mm and $\mathbf{b}$ energy distribution on the section closed to the beam waist and the main parameters obtained by the experimental characterization

of the Section 2 were done at three power levels $(1250 \mathrm{~W}$, $1500 \mathrm{~W}, 2500 \mathrm{~W}$ ) in order to establish the laser power necessary to obtain full penetration. Afterward, this level of power was used for the dissimilar welding.

\section{Results and discussion}

\subsection{Case study \#1: bead on plate penetration test on Ti-6Al-4V}

Figure 5 shows temperature contour plots and fluid flow in terms of velocity vectors on the transverse section (Fig. 5a, c, e) - plane equation: $x=15 \mathrm{~mm}$ - and on the top surface (Fig. 5b, d, f), plane equation: $z=0$, in the case of the autogenous laser welding of Ti-6Al-4V at the three levels of laser power adopted in the present study. The dashed white line in the figures represents the locus of points where the temperature is equal to the melting temperature $T_{\mathrm{L}}$ of Ti6Al-4V reported in Table 1, assumed as the boundary between the weld pool and the original material.

The simulations showed that melted material at the top surface moves outward as the weld pool tends to widen. In addition, a transverse cross section showed a circulation loop of fluid near the top surface. Both mechanisms are attributed to the Marangoni forces in the weld pool. The effects of these
Fig. 4 A picture of the experimental set-up based on a fiber laser source used to weld the specimen

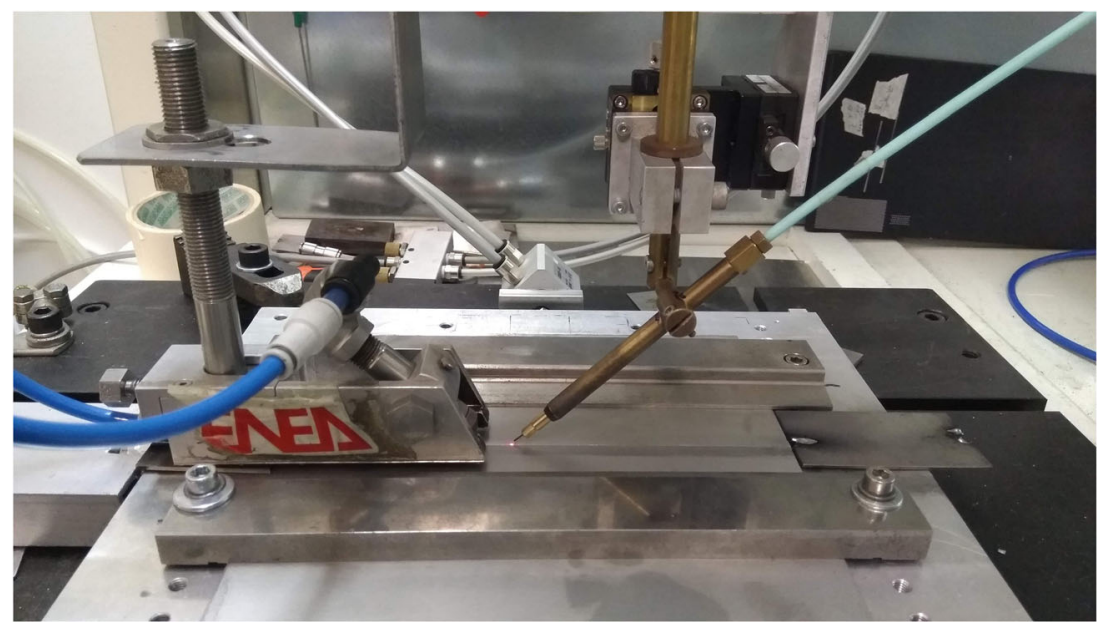


Table 6 Chemical composition (in wt $\%$ ) of the base materials

\begin{tabular}{ccccccccccc}
\hline & & \multicolumn{10}{c}{ Ti-6Al-4V } & & & & \\
& $\mathrm{V}$ & $\mathrm{Al}$ & $\mathrm{Fe}$ & $\mathrm{O}$ & $\mathrm{N}$ & $\mathrm{H}$ & $\mathrm{Ti}$ & & & \\
Min & 3.5 & 5.5 & 0 & 0 & 0 & 0 & Balance & & & \\
Max & 4.5 & 6.8 & 0.3 & 0.2 & 0.05 & 0.015 & & & & \\
& & & & \multicolumn{7}{c}{ Inconel 718} \\
& $\mathrm{Ni}$ & $\mathrm{Cr}$ & $\mathrm{Mo}$ & $\mathrm{Nb}$ & $\mathrm{Co}$ & $\mathrm{Mn}$ & $\mathrm{Cu}$ & $\mathrm{Al}$ & $\mathrm{Ti}$ & $\mathrm{Fe}$ \\
Min & 50 & 17 & 2.8 & 4.75 & 0 & 0 & 0 & 0.2 & 0.65 & Balance \\
Max & 55 & 21 & 3.3 & 5.5 & 1 & 0.35 & 0.3 & 0.8 & 1.15 & \\
\hline
\end{tabular}

Marangoni forces were also apparent at the bottom surface, in the case of full penetration $(P=2500 \mathrm{~W})$, resulting in a wider weld width with respect to the centerline of the weld pool.

As expected, the higher the laser power, the higher the fluid flow velocities, due to the increased Marangoni forces. The maximum velocities near the top surfaces are equal to 0.312 $\mathrm{m} / \mathrm{s}, 0.414 \mathrm{~m} / \mathrm{s}$, and $0.440 \mathrm{~m} / \mathrm{s}$ for a laser power of $1.25 \mathrm{~kW}$, $1.5 \mathrm{~kW}$, and $2.5 \mathrm{~kW}$, respectively.

The model parameters reported in Table 4 were calibrated by comparing experimental images and simulation results at the three laser powers used in the present study. Figure 6 compares the experimental and numerical results by overlapping a picture of the weld pool (obtained through the
Fig. 5 Temperature profile and velocity diagram for the bead on plate penetration test on Ti-6Al$4 \mathrm{~V}$ : a transverse section, $P=1.25 \mathrm{~kW} ; \mathbf{b}$ top surface, $P=1.25 \mathrm{~kW} ; \mathbf{c}$ transverse section, $P=1.5 \mathrm{~kW} ; \mathbf{d}$ top surface, $P=1.5$ $\mathrm{kW}$; e transverse section, $P=2.5$ $\mathrm{kW}$;

f top surface, $P=2.5 \mathrm{~kW}$
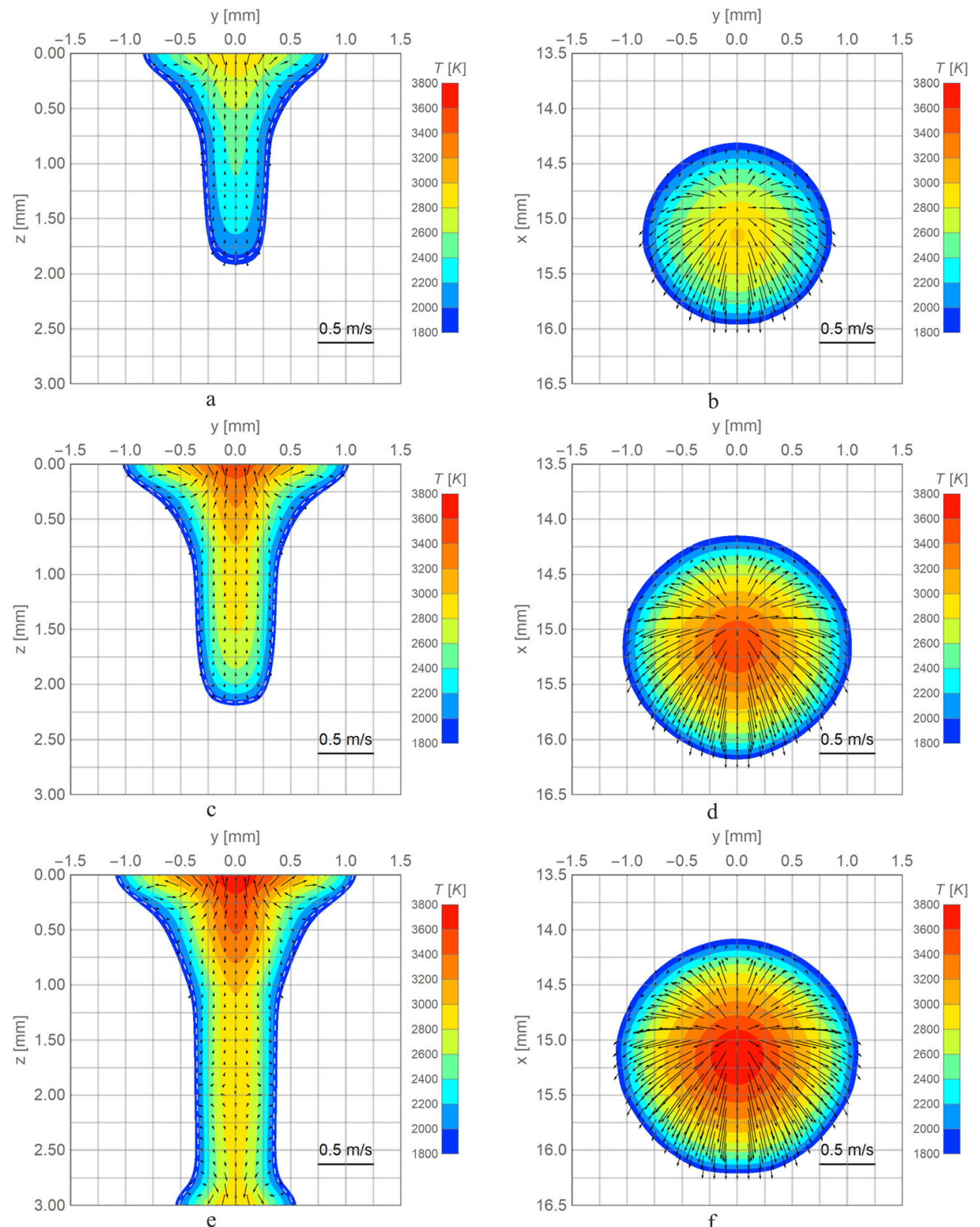


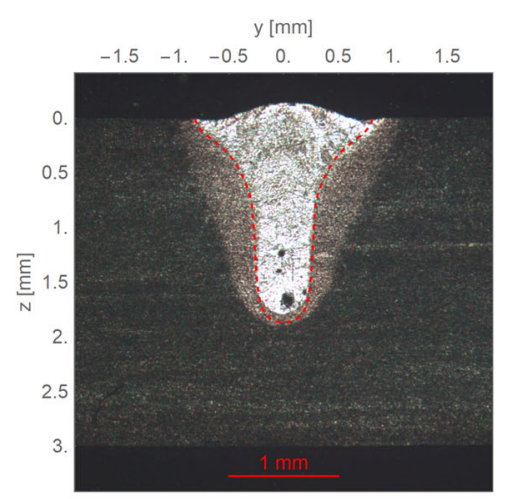

a

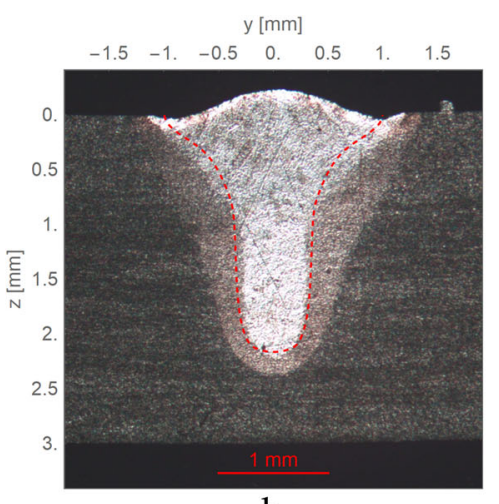

b

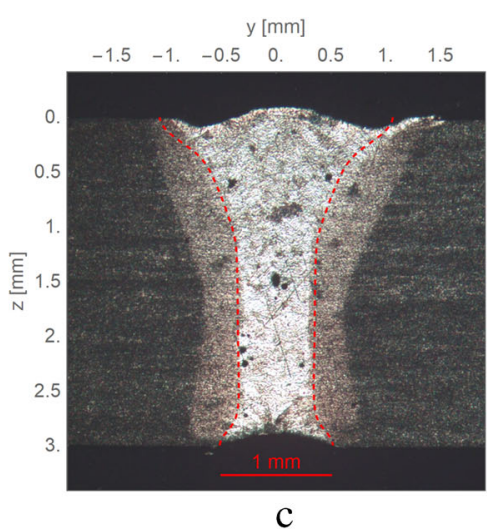

Fig. 6 Comparison between the experimental and simulated transverse sections for the bead on plate penetration test on Ti-6Al-4V at three different laser powers: a $P=1250 \mathrm{~W}, \mathbf{b} P=1500 \mathrm{~W}$, and $\mathbf{c} P=2500 \mathrm{~W}$

extraction of a specimen by cutting and polishing operations) and the border of the weld pool itself (the dashed red line, extracted from the numerical data as the locus of the points where the melting temperature of the Ti-6Al-4V occurred during the simulated process). From Fig. 6, one will notice high levels of agreement, both in terms of weld pool shape and dimensions.

Figure 7 summarizes the main numerical results. In particular, at the three different laser powers considered in the simulations, Fig. 7a shows the shape and dimensions of the weld pool on the transverse section, while Fig. $7 \mathrm{~b}$ demonstrates the border between the melted and solid parts at the generic instant of the simulated stationary welding process. Finally, Fig. 7c depicts how the laser power affects weld pool dimensions-i.e., the weld width and depth. The maximum difference observed between experimental and numerical results was $0.07 \mathrm{~mm}$ (4\% of the experimental value) and $0.32 \mathrm{~mm}$ (14\% of the experimental value) for the weld pool depth and width, respectively. As expected, the higher the laser power, the wider and deeper the weld pool, but results show a significantly higher effect on the depth. This demonstrates that the keyhole depth is the most important parameter affecting the weld pool shape in laser welding.

\subsection{Case study \#2: bead on plate penetration test on Inconel 718}

Figure 8 shows the temperature contour plots and fluid flow in terms of velocity vectors on the transverse section (Fig. 8a, c, e) - plane equation: $x=15 \mathrm{~mm}$ - and on the top surface (Fig. 8b, d, f), plane equation: $z=0$, in the case of the autogenous laser welding of Inconel 718 at the three levels of laser power adopted in the present study. The dashed white line in the figures represents the locus of points where the temperature is equal to the melting temperature of Inconel 718 reported in Table 1, assumed as the boundary between the weld pool and the original material.

The fluid velocity at the top surface of the weld pool is outward due to Marangoni forces, similar to observations made with Ti-6Al-4V. In the case of full penetration, obtained at the laser power of $2.5 \mathrm{~kW}$, Marangoni effects are observed both at the top and bottom surfaces of the weld pool. Maximum velocities near the top surfaces are equal to 0.181 $\mathrm{m} / \mathrm{s}, 0.186 \mathrm{~m} / \mathrm{s}$, and $0.211 \mathrm{~m} / \mathrm{s}$ for the laser power of $1.25 \mathrm{~kW}$, $1.5 \mathrm{~kW}$, and $2.5 \mathrm{~kW}$, respectively. The lower fluid flow velocities in Inconel 718 can be attributed to weaker Marangoni forces, a result that seems to be confirmed by the narrower weld pool.

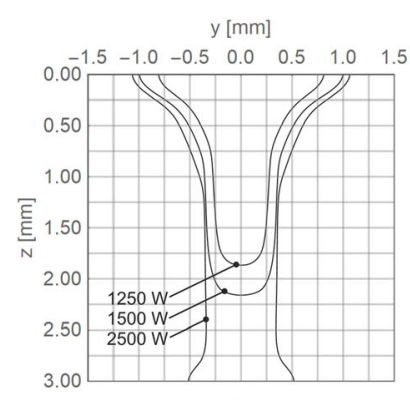

a
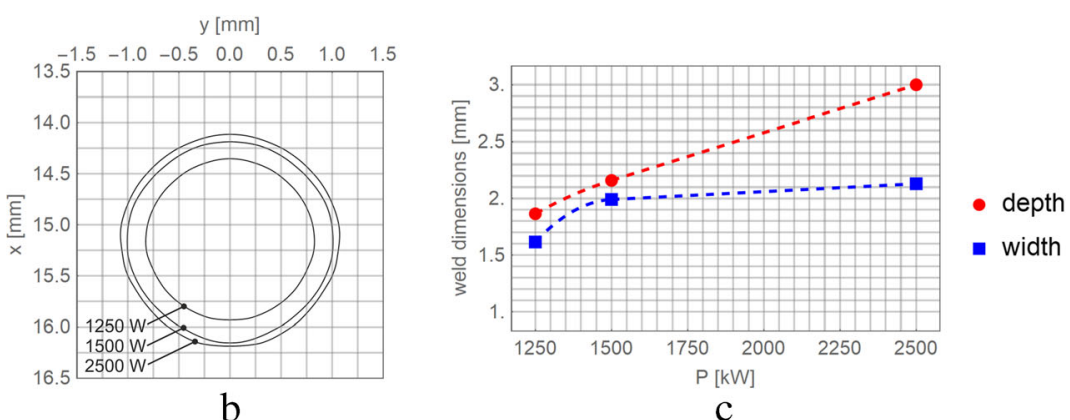

Fig. 7 Weld pool shape and dimensions obtained by numerical simulations for the bead on plate penetration test on Ti- $6 \mathrm{Al}-4 \mathrm{~V}$ : a transverse section, $\mathbf{b}$ top surface, $\mathbf{c}$ depth and width of the weld pool vs laser power 
Fig. 8 Temperature profile and velocity diagram for the bead on plate penetration test on Inconel 718: a transverse section, $P=1.25$ $\mathrm{kW}$; $\mathbf{b}$ top surface, $P=1.25 \mathrm{~kW}$; transverse section, $P=1.5 \mathrm{~kW}$; d top surface, $P=1.5 \mathrm{~kW}$, e transverse section, $P=2.5 \mathrm{~kW}$, and $\mathbf{f}$ top surface, $P=2.5 \mathrm{~kW}$
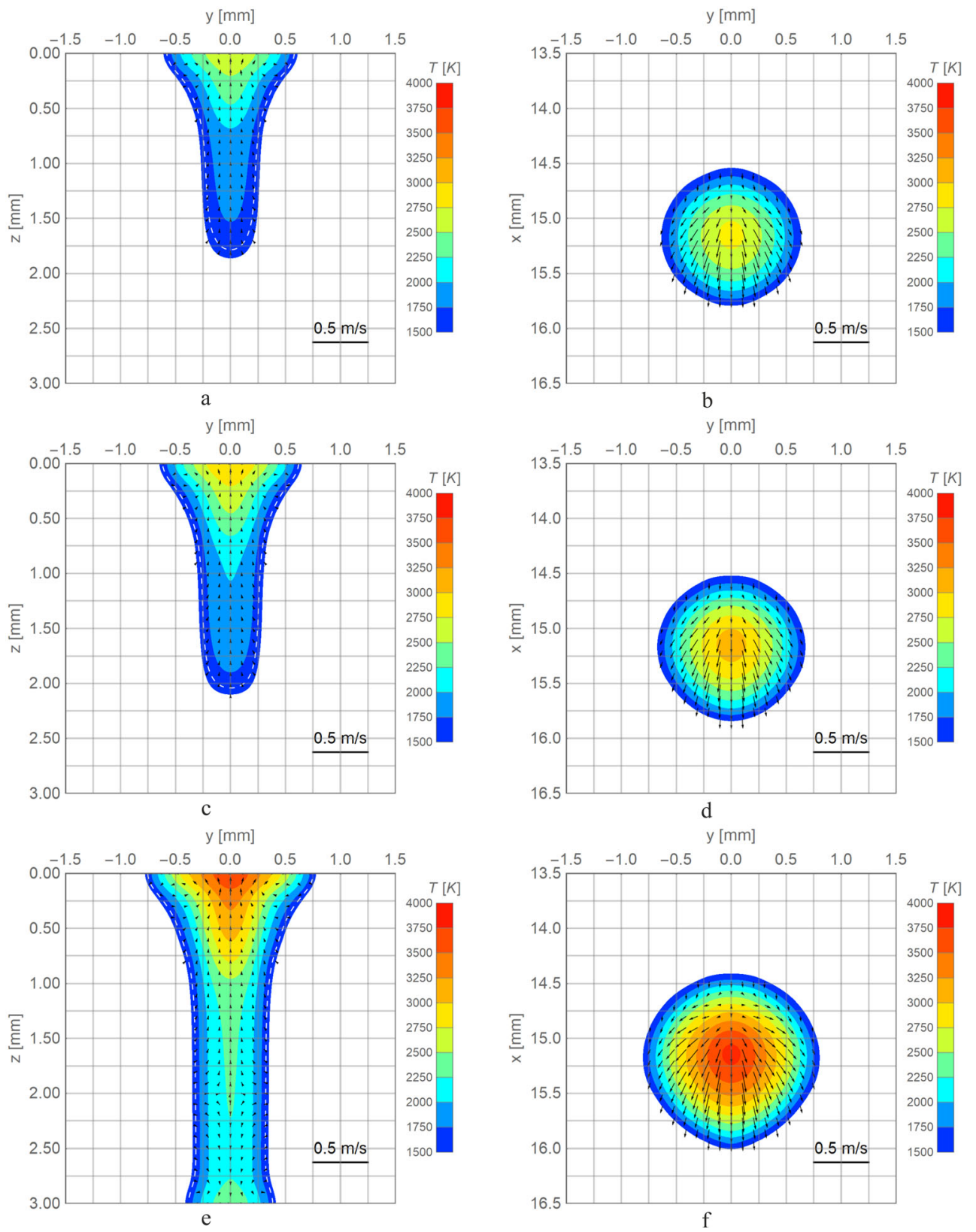

The model parameters reported in Table 3 were calibrated in the same way as those for the Ti- $6 \mathrm{Al}-4 \mathrm{~V}$, and a comparison between experimental and numerical results is reported in Fig. 9. Figure 10 summarizes the main numerical results. The maximum difference observed between experimental and numerical results was $0.04 \mathrm{~mm}$ (2\% of the experimental value) and $0.34 \mathrm{~mm}$ (22\% of the experimental value) for the weld pool depth and width, respectively.

\subsection{Case study \#3: dissimilar butt joint welding of Ti- 6Al-4V and Inconel 718}

Figure 11 shows temperature contour plots and fluid flow in terms of velocity vectors on the transverse section (Fig. 11a, c)-plane equation: $x=15 \mathrm{~mm}$ - and the top surface (Fig. 11b, d), plane equation: $z=0$, in the case of the dissimilar laser welding of Ti-6Al-4V and Inconel 718. Simulations were carried out at the laser power of $2.5 \mathrm{~kW}$, which was established as the power necessary to provide full penetration in the autogenous welding of both materials. Two different models were used. The first one (Fig. 11a, b) does not consider diffusion phenomena occurring at high temperatures, whereas the second model (Fig. $11 \mathrm{c}, \mathrm{d}$ ) includes species equations (last equation of Table 2). In the latter model-which is able to consider diffusion and mixing phenomena in the simulations - the local physical and thermal properties of the material in the weld pool are calculated, based on the 

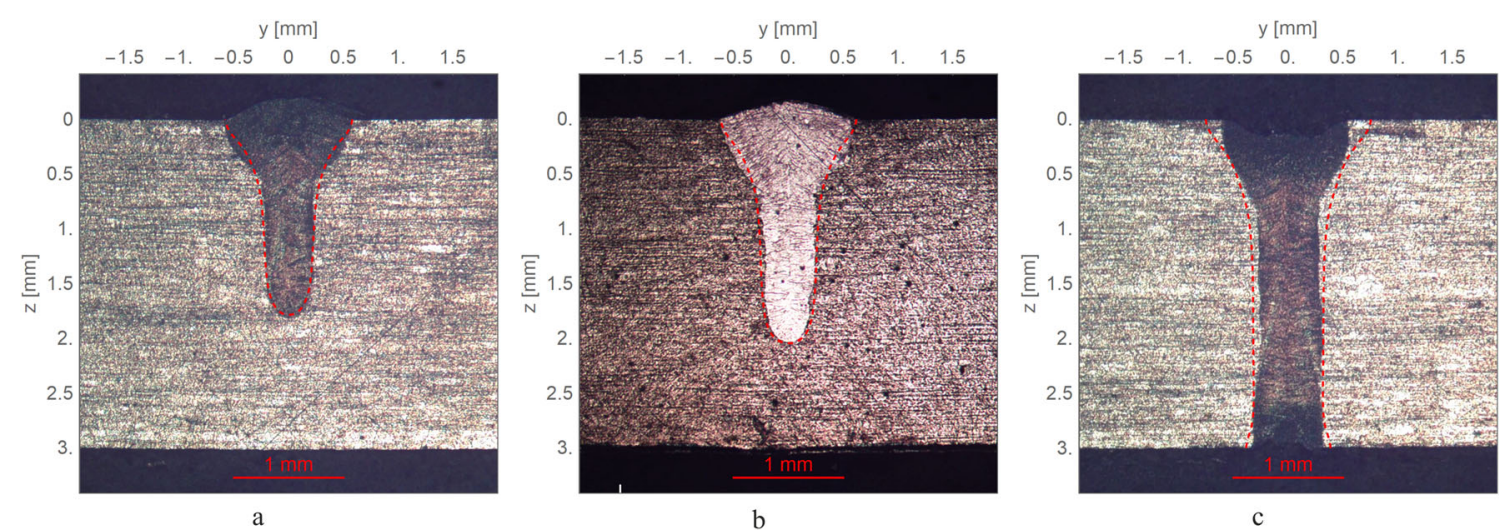

Fig. 9 Comparison between the experimental and simulated transverse sections for the bead on plate penetration test on Inconel 718 at three different laser powers: (a) $P=1250 \mathrm{~W}$, (b) $P=1500 \mathrm{~W}$, and (c) $P=2500 \mathrm{~W}$

species fraction, by a mass-weighted mixture law. The white dashed line in the transverse sections (Fig. 11a, c) represents the boundary of the weld pool; it was calculated in the same way as it was for the autogenous weldings, but in this case, it was necessary to use a different melting temperature for each side. The inclusion of the species equation resulted in a more gradual change to the physical and thermal properties of the weld pool, and the resulting shape was more symmetrical as a result of the numerical simulations.

Despite the difficulties due to the determination of fluid flow in the weld pool, the obtained outcomes resulted to be reliable based on the fluid flow patterns validated in previous work [19, 20, 23].

Figure 12 shows the temperature and velocity vector magnitude distribution at the intersection between the top surface and the orthogonal plane parallel to the $y$-axis (i.e., orthogonal to the welding direction) and containing the point where the laser is applied. Both simulation results - those without (nomix, blue curves) and with (mix, orange curves) species equations - are reported in Fig. 12. The differences between white and blue curves are due to the effect of mixing on physical properties in the weld pool. Due to its higher thermal conductivity, a steeper temperature gradient is observed on the nickel side, which implied a narrower weld pool (Fig. 12a). Temperature gradients are expected to play an important role in the development of residual stresses during the cooling stage. The residual stress prediction goes beyond the scope of the present study; in fact, the numerical models were not able to consider this specific effect. Nevertheless, this aspect of the experiment could be a subject for future numerical and experimental investigation, with the goal of obtaining a deeper understanding of the dissimilar welding process. Figure $12 \mathrm{~b}$ shows that, due to the higher Marangoni effects, the maximum velocity achieved is approximately three times higher on the titanium side when the species equations are not taken into account. On the other hand, this difference disappears when the species equations are included in the simulations, although the area where high velocity vectors occur is still wider.

Figure 13 shows the contour plots of mass fractions at the transverse section (Fig. 13a) and the top surface (Fig. 13b) of the weld pool. There are two basic mechanisms that govern mass transportation in the weld pool: mass diffusion and fluid convection. The prevalence between these mechanisms can be estimated by the Peclet number $P_{\mathrm{e}}$, which can be calculated as:

$P_{\mathrm{e}}=\frac{V_{\max } L_{C}}{D}$

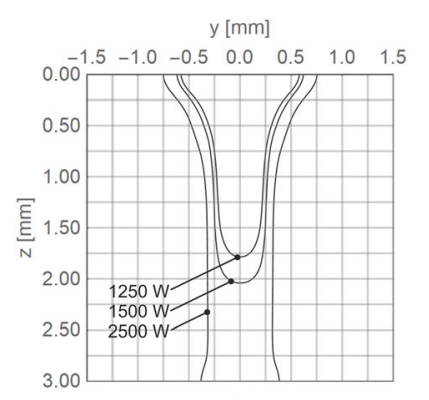

a

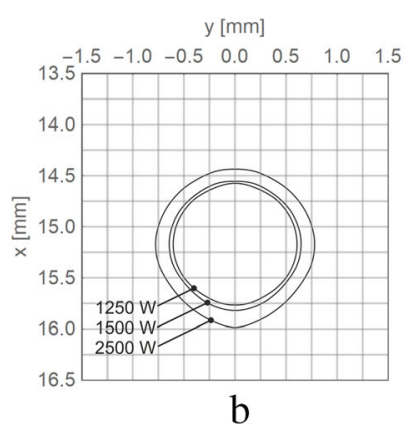

b

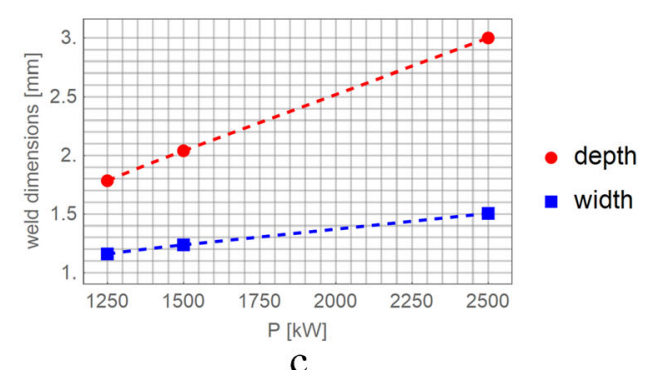

Fig. 10 Weld pool shape and dimensions obtained by numerical simulations for the bead on plate penetration test on Inconel 718 : (a) transverse section, (b) top surface, (c) and depth and width of the weld pool vs laser power 

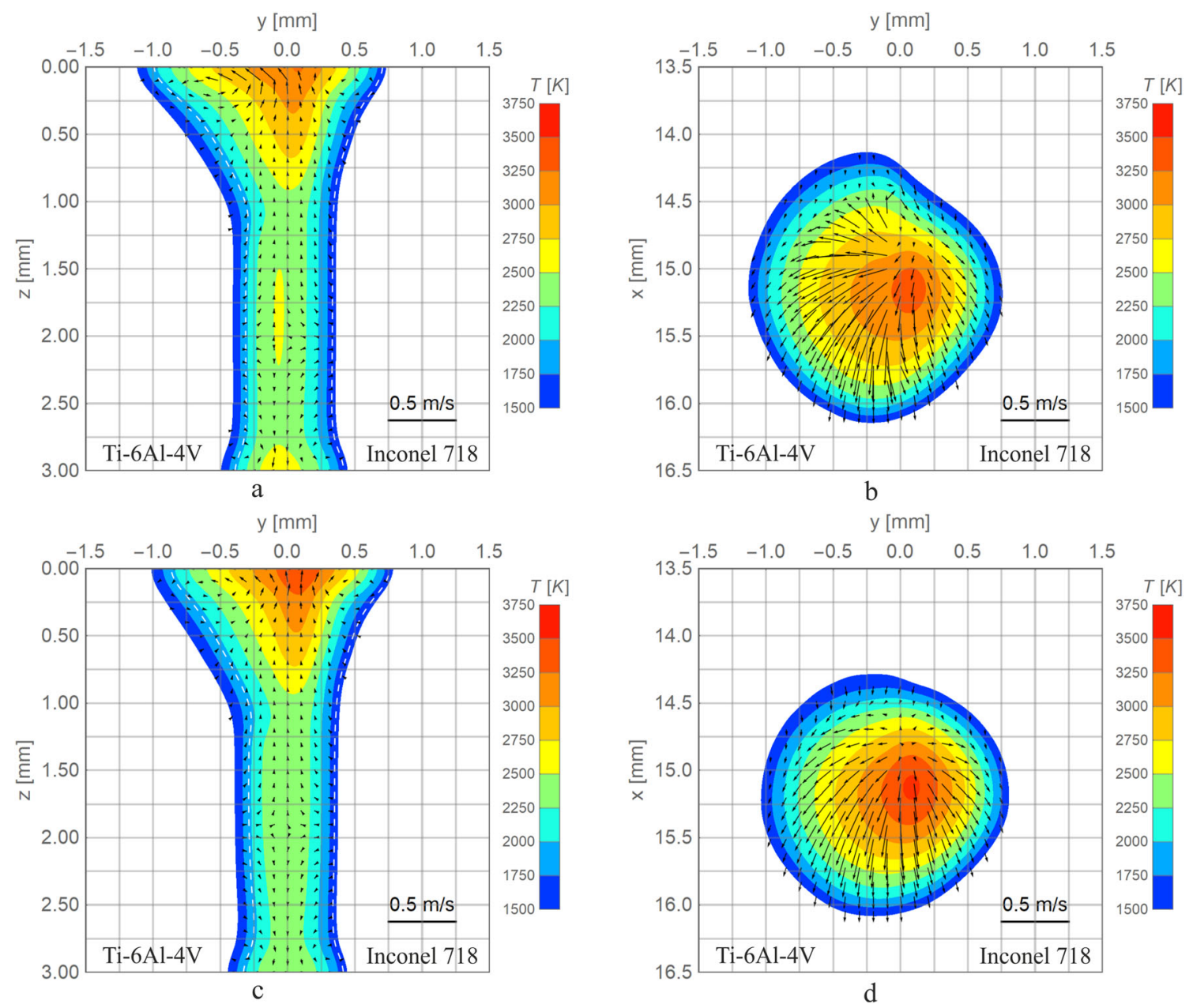

Fig. 11 Temperature profile and velocity diagram for the dissimilar welding of Ti-6Al-4V and Inconel 718 obtained by a laser power of 2.5 $k W$ : transverse section (a) and top surface (b) without including species

In the specific case of the present study, the characteristic length $L_{\mathrm{C}}$ can be assumed as equal to half the width of the weld pool, while $P_{\mathrm{e}}$ resulted to be approximately $10^{3}$, meaning that mass distribution in the weld pool is mostly driven by fluid convection, whereas mass diffusion plays a secondary role.

equations in the simulations; transverse section (c) and top surface (d) including species equations in the simulations

A comparison between the numerical and experimental results for the dissimilar laser welding of Ti-6Al-4V to Inconel 718 showed good agreement-as depicted in Fig. 14-both in the cases where species equations were included and in those where they were not. In particular, Fig. 14a shows an overlap of a picture obtained by an
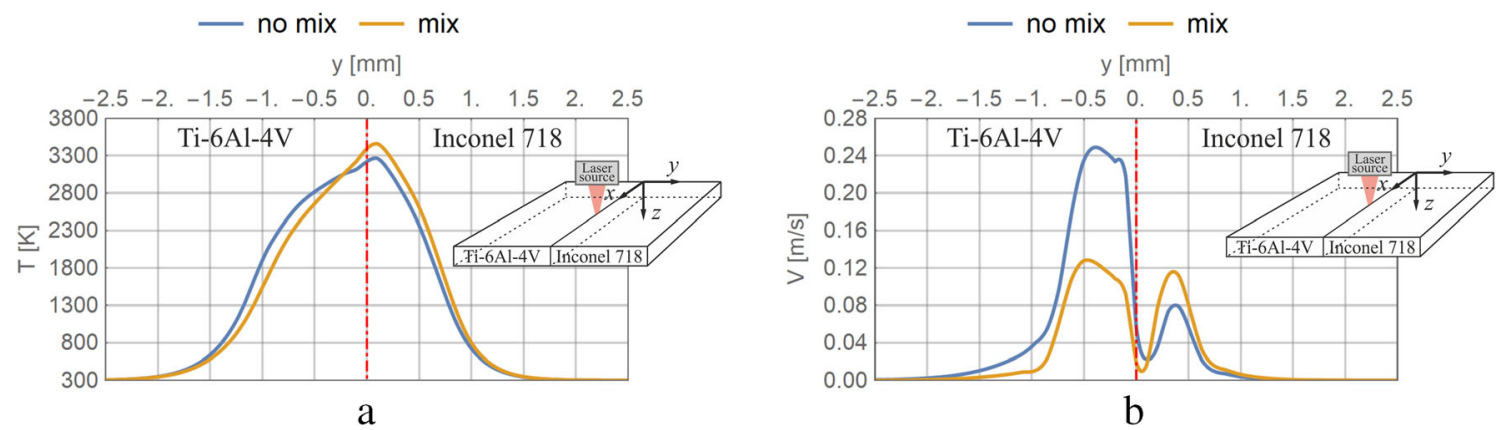

Fig. 12 Temperature profile (a) and velocity modulus distribution (b) along the $y$-axis of the top surface, in the two cases where species equations are (mix) and are not (no mix) taken into account in simulations of the dissimilar welding of Ti-6Al-4V and Inconel 718 


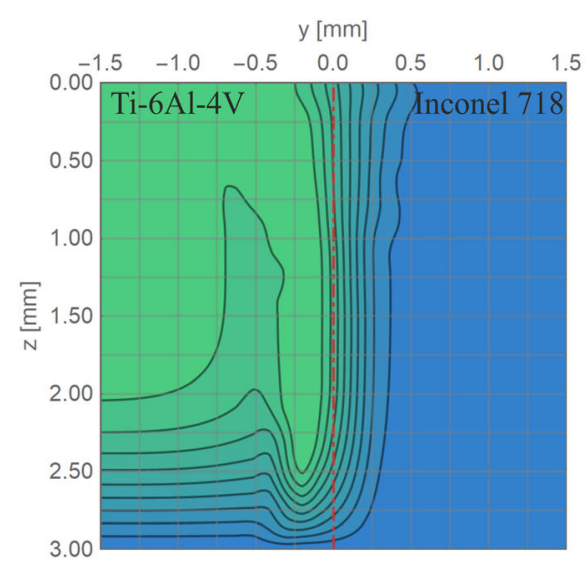

a

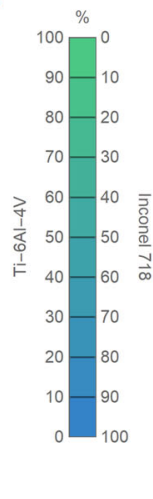

b

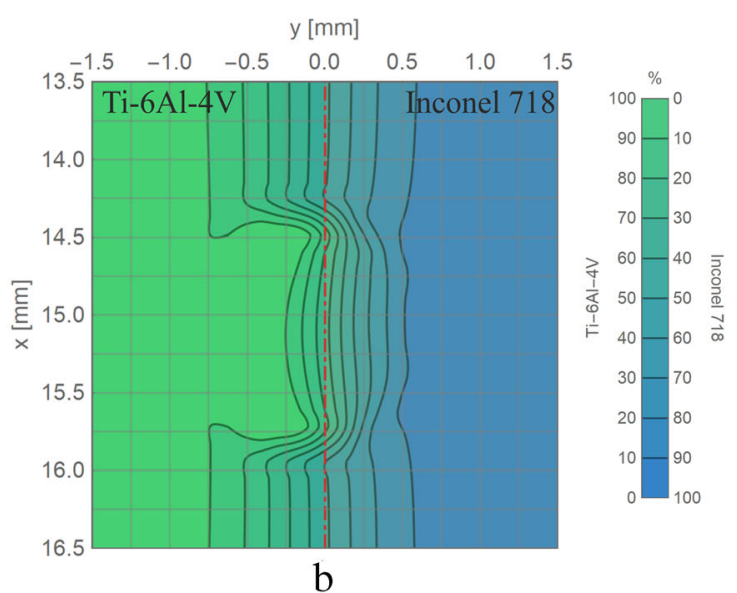

Fig. 13 Mass fraction contour plots in the weld pool at the transverse section (a) and the top surface (b) for dissimilar laser welding of Ti-6Al-4V and Inconel 718

optical microscope of the weld pool with the numerical results obtained in three different ways:

- White dashed line: Ti-6Al-4V and Inconel 718 melting temperatures were imposed on the left and right, respectively. No species equations were included in the simulations.

- Blue dashed line: Ti-6Al-4V and Inconel 718 melting temperatures were imposed on the left and right, respectively. Species equations were included in the simulations.

- Red dashed line: Local melting temperature of the material was calculated by using the mass-weighted mixture law,

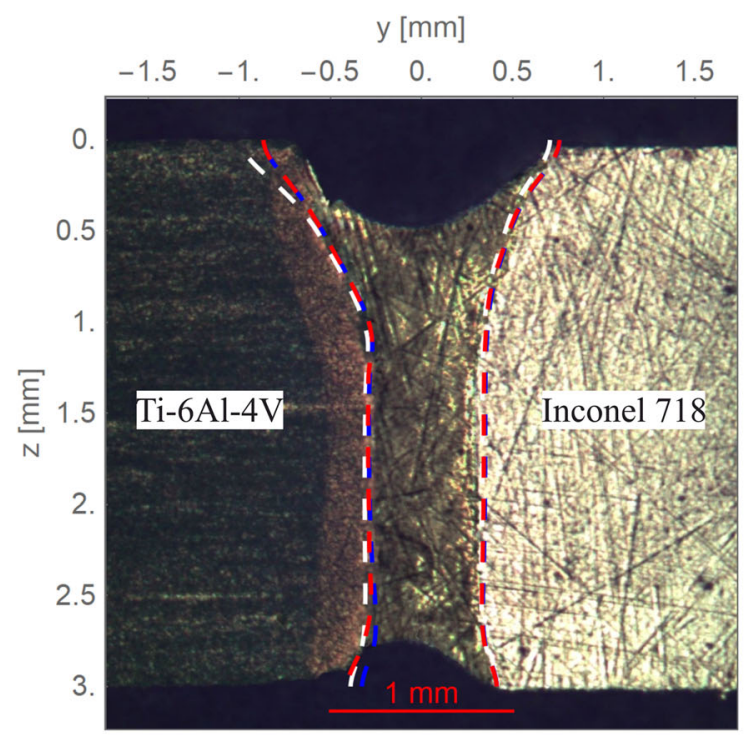

a

Fig. 14 Comparison between the experimental and simulated transverse sections for the dissimilar laser welding: (a) boundaries of the weld pool drawn by fixing the melting temperature of the two pure alloys without the species equations (white dashed line) and with the species equations (blue dashed line) and by fixing the effective local melting temperature obtained when species equations were included in the simulations.

No significant difference can be observed between the three lines, given that at the weld pool boundaries the composition of materials is quite close to $100 \%$ of one of the two alloys. The maximum difference observed was $0.29 \mathrm{~mm}(21 \%$ of the experimental value) and $0.22 \mathrm{~mm}$ (15\% of the experimental value), respectively, when the species equations were not included and when they were. The maximum difference occurred at the top surface, where most of the imperfections of

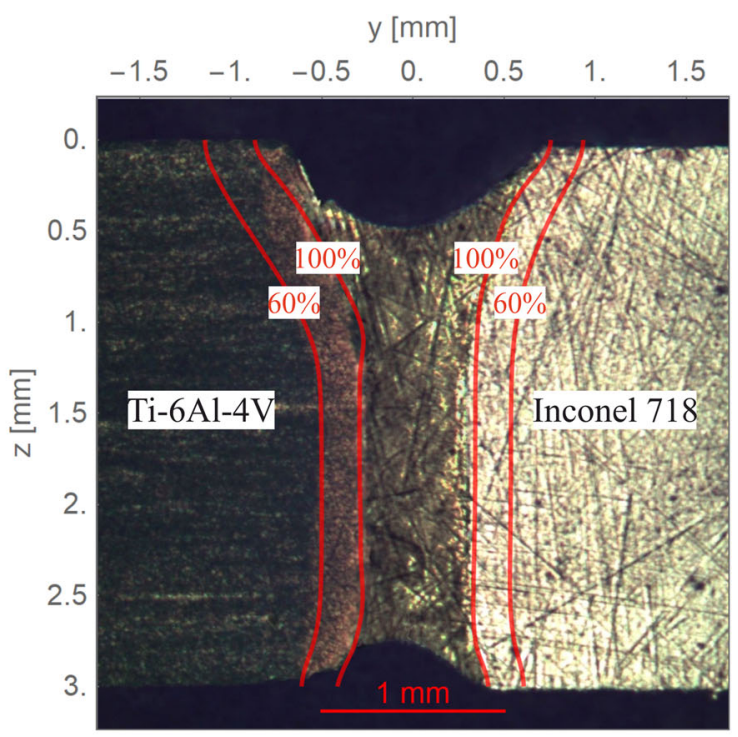

b

while assuming the mass-weighted mixture law (red dashed line); (b) identification of the HAZ by drawing (red continuous) lines at the point where the temperature reaches a specific fraction of the effective local melting temperature 
the welding occurred. Therefore, it is reasonable to assume that if the welding process were improved, the model applied in the numerical simulations would provide better results. The model developed in the present study to simulate dissimilar welding, however, based on previous calibrations on pure alloys, did give quite consistent results.

Another possible application of the numerical results is shown in Fig. 14b, where the red continuous lines represent the points where the temperature reaches a specific percentage of the local melting temperature. In the specific case of Ti$6 \mathrm{Al}-4 \mathrm{~V}$, for which the polishing operation resulted enough to highlight different metallurgical structures for simple optical microscopy observations, it was possible to identify the heataffected zone (HAZ) boundaries with a good level of accuracy when $60 \%$ and $100 \%$ contours of the local melting temperature were drawn. The $60 \%$ of the melting temperature corresponds to the $\beta$-transus temperature $(1155 \mathrm{~K})$ in the Ti-Al state diagram [41].

\section{Conclusions}

In this paper, a three-dimensional model capable of simulating heat transfer, mass transfer, and fluid flow was developed. Temperature history, mass distribution, and velocity field in the weld pool were evaluated in three welding cases: the autogenous laser welding of Ti-6Al-4V, the autogenous laser welding of Inconel 718, and the dissimilar laser welding of Ti-6Al-4V and Inconel 718. The weld pool shape and its dimensions were evaluated at three different laser power levels for the autogenous weldings, whereas only the maximum laser power (that allows full penetration of both materials) was considered for the dissimilar welding.

The main outcomes achieved in the present paper are the following.

- For all the investigated cases, the Marangoni effects, implying fluid circulation in the transverse section and outward flow at the top surface of the joint, resulted to be the dominant phenomenon, as shown in Figs. 5, 8, and 12.

- Good agreement between the simulated and experimental results, in terms of weld pool shape and dimensions, demonstrates the reliability and ability of both the volumetric heat source model and numerical model adopted in this study.

- Weld pool width and depth both increase with an increase in laser power, but the effect on the depth is more significant than on the width, given the deeper keyhole depth created as a result of the higher laser power.

- As depicted in Fig. 11a, the inclusion of the species transport equations in the simulations of the dissimilar welding implied only small changes on the weld pool, which shows however a slight better agreement between the numerical and experimental results.

- The dissimilar welding simulations showed a higher temperature gradient in the nickel side, due to its higher thermal conductivity. Temperature gradients are expected to play an important role in the development of residual stresses during the cooling stage. This aspect, which goes beyond the scope of the present study, could be object of future numerical and experimental investigation, with the goal to obtain a deeper understanding of the dissimilar welding process.

- The use of species equations in simulating the dissimilar welding dropped significantly the maximum velocity difference between the two base materials, which is approximately 3 times higher in Ti-6Al-4V than in Inconel 718 when these equations are not included in the simulations. Nevertheless, the area where the velocity is close to the maximum value is still wider in Ti-6Al-4V than in Inconel 718.

In conclusion, the robustness and consistency of the numerical models proposed by this study should provide powerful tools to develop and improve innovative welding joints such as the one hereby analyzed, involving two important materials relevant to aeronautic applications-i.e., Ti-6Al$4 \mathrm{~V}$ and Inconel 718. By further enhancing and refining the numerical model, other fundamental aspects could be included in the simulations, such as the residual stress states, which could provide a wider understanding of the welding process. In this case, the investigation would not be limited to the results derived from fluid dynamic variables but could expand the query to include mechanical aspects that are essential in the design of components involving advanced joints.

Code availability Custom codes where implemented in a commercial software as explained in details in the manuscript.

Consent to participate Not applicable to this study. It does not involve neither human subjects nor vulnerable groups with potential for coercion.

Consent to publish The authors give their consent for the publication of identifiable details, which can include photograph(s) and/or videos and/or case history and/or details within the text ("Material") to be published in the journal and article. The authors confirm that they have seen and been given the opportunity to read both the material and the article to be published. The authors understand that the journal may be available in both print and on the Internet and will be available to a broader audience through marketing channels and other third parties. Therefore, anyone can read the material published in the journal.

Authors' contribution Dr. Amir Hossein Faraji: Principal investigator

Dr. Luigi Bruno and Dr. Carmine: Funding acquisition, formulation of research goals and aims, and writing/draft preparation

Dr Giuseppe Barbieri and Eng. Francesco Cognini: Experimental activities (laser welding and microstructure analysis) 
Funding Open access funding provided by Università della Calabria within the CRUI-CARE Agreement. This work was supported by the Italian Ministry of Education, University and Research (MIUR), by way of grant PRIN-2015PN8CEA.

Data availability I think that all relevant data to check the accuracy/ robustness of our results have been included in the result section of the manuscript. Anyway we can add additional raw data if needed.

\section{Declarations}

Conflict of interest The authors declare no competing interests.

Open Access This article is licensed under a Creative Commons Attribution 4.0 International License, which permits use, sharing, adaptation, distribution and reproduction in any medium or format, as long as you give appropriate credit to the original author(s) and the source, provide a link to the Creative Commons licence, and indicate if changes were made. The images or other third party material in this article are included in the article's Creative Commons licence, unless indicated otherwise in a credit line to the material. If material is not included in the article's Creative Commons licence and your intended use is not permitted by statutory regulation or exceeds the permitted use, you will need to obtain permission directly from the copyright holder. To view a copy of this licence, visit http://creativecommons.org/licenses/by/4.0/.

\section{References}

1. Quintino L, Costa A, Miranda R, Yapp D, Kumar V, Kong CJ (2007) Welding with high power fiber lasers - a preliminary study. Mater Des 28:1231-1237. https://doi.org/10.1016/j.matdes.2006. 01.009

2. Salminen A, Piili H, Purtonen T (2010) The characteristics of high power fibre laser welding. Proc Inst Mech Eng C J Mech Eng Sci 224:1019-1029. https://doi.org/10.1243/09544062JMES1762

3. Akman E, Demir A, Canel T, Sinmazçelik T (2009) Laser welding of Ti6Al4V titanium alloys. J Mater Process Technol 209:37053713. https://doi.org/10.1016/j.jmatprotec.2008.08.026

4. Casalino G, Mortello M, Campanelli SL (2015) Ytterbium fiber laser welding of Ti6Al4V alloy. J Manuf Process 20:250-256. https://doi.org/10.1016/j.jmapro.2015.07.003

5. Liu J, Liu H, Gao X-L, Yu H (2020) Microstructure and mechanical properties of laser welding of Ti6Al4V to Inconel 718 using $\mathrm{Nb} / \mathrm{Cu}$ interlayer. J Mater Process Technol 277:116467. https://doi.org/10. 1016/j.jmatprotec.2019.116467

6. Chen H-C, Pinkerton AJ, Li L (2011) Fibre laser welding of dissimilar alloys of Ti-6Al-4V and Inconel 718 for aerospace applications. Int J Adv Manuf Technol 52:977-987. https://doi.org/10. 1007/s00170-010-2791-3

7. Xue Z, Hu S, Zuo D, Cai W, Lee D, Elijah KA Jr (2013) Molten pool characterization of laser lap welded copper and aluminum. J Phys D Appl Phys 46:46. https://doi.org/10.1088/0022-3727/46/ 49/495501

8. Chatterjee S, Abinandanan TA, Chattopadhyay K (2006) Microstructure development during dissimilar welding: Case of laser welding of $\mathrm{Ti}$ with $\mathrm{Ni}$ involving intermetallic phase formation. J Mater Sci 41:643-652. https://doi.org/10.1007/s10853-0066480-4

9. Faraji AH, Bahmani A, Goodarzi M, Seyedein SH, Shabani MO (2014) Numerical and experimental investigations of weld pool geometry in GTA welding of pure aluminum. J Cent South Univ 21:20-26. https://doi.org/10.1007/s11771-014-1910-y

10. Faraji AH, Goodarzi M, Seyedein SH, Zamani MH (2014) Experimental study and numerical modeling of arc and weld pool in stationary GTA welding of pure aluminum. Int J Adv Manuf Technol 71:2059-2071. https://doi.org/10.1007/s00170-0145651-8

11. Dong W, Lu S, Li D, Li Y (2011) GTAW liquid pool convections and the weld shape variations under helium gas shielding. Int $J$ Heat Mass Transf 54:1420-1431. https://doi.org/10.1016/j. ijheatmasstransfer.2010.07.069

12. Dong W, Lu S, Li D, Li Y (2010) Modeling of the weld shape development during the autogenous welding process by coupling welding arc with weld pool. J Mater Eng Perform 19:942-950. https://doi.org/10.1007/s11665-009-9570-Z

13. Bag S, Trivedi A, De A (2009) Development of a finite element based heat transfer model for conduction mode laser spot welding process using an adaptive volumetric heat source. Int J Therm Sci 48:1923-1931. https://doi.org/10.1016/j.ijthermalsci.2009.02.010

14. Vishnu PR, Li WB, Easterling KE (1991) Heat flow model for pulsed welding. Mater Sci Technol (United Kingdom) 7:649-659. https://doi.org/10.1179/mst.1991.7.7.649

15. Van Elsen M, Baelmans M, Mercelis P, Kruth J-P (2007) Solutions for modelling moving heat sources in a semi-infinite medium and applications to laser material processing. Int J Heat Mass Transf 50: 4872-4882. https://doi.org/10.1016/j.ijheatmasstransfer.2007.02. 044

16. Winczek J, Modrzycka A, Gawrońska E (2016) Analytical description of the temperature field induced by laser heat source with any trajectory. In: Procedia Engineering. pp 553-558

17. Phanikumar G, Chattopadhyay K, Dutta P (2001) Modelling of transport phenomena in laser welding of dissimilar metals. Int $\mathrm{J}$ Numer Methods Heat Fluid Flow 11:156-171. https://doi.org/10. $1108 / 09615530110381575$

18. Mukherjee S, Chakraborty S, Galun R, Estrin Y, Manna I (2010) Transport phenomena in conduction mode laser beam welding of Fe-Al dissimilar couple with Ta diffusion barrier. Int J Heat Mass Transf 53:5274-5282. https://doi.org/10.1016/j.ijheatmasstransfer. 2010.07.032

19. Shaibu VB, Sahoo SK, Kumar A (2015) Computational modeling of dissimilar metal CO2 laser welding: applied to copper and 304 stainless steel. In: Procedia Engineering. pp 208-214

20. Phanikumar G, Dutta P, Chattopadhyay K (2004) Computational modeling of laser welding of $\mathrm{Cu}-\mathrm{Ni}$ dissimilar couple. Metall Mater Trans B Process Metall Mater Process Sci 35:339-350. https://doi. org/10.1007/s11663-004-0034-4

21. Rai R, Burgardt P, Milewski JO, Lienert TJ, DebRoy T (2009) Heat transfer and fluid flow during electron beam welding of $21 \mathrm{Cr}-6 \mathrm{Ni}-$ 9Mn steel and Ti-6Al-4V alloy. J Phys D Appl Phys 42:025503. https://doi.org/10.1088/0022-3727/42/2/025503

22. Hu Y, He X, Yu G, Ge Z, Zheng C, Ning W (2012) Heat and mass transfer in laser dissimilar welding of stainless steel and nickel. Appl Surf Sci 258:5914-5922. https://doi.org/10.1016/j.apsusc. 2012.02.143

23. Métais A, Matteï S, Tomashchuk I, Cicala E, Gaied S (2017) Dissimilar steels laser welding: experimental and numerical assessment of weld mixing. J Laser Appl 29:022420. https://doi.org/10. 2351/1.4983168

24. Esfahani MRN, Coupland J, Marimuthu S (2015) Numerical simulation of alloy composition in dissimilar laser welding. J Mater Process Technol 224:135-142. https://doi.org/10.1016/j. jmatprotec.2015.05.005

25. Ribic B, Rai R, DebRoy T (2008) Numerical simulation of heat transfer and fluid flow in GTA/Laser hybrid welding. Sci Technol Weld Join 13:683-693. https://doi.org/10.1179/ $136217108 X 356782$ 
26. Traidia A, Roger F (2011) Numerical and experimental study of arc and weld pool behaviour for pulsed current GTA welding. Int $\mathrm{J}$ Heat Mass Transf 54:2163-2179. https://doi.org/10.1016/j. ijheatmasstransfer.2010.12.005

27. Rai R, Kelly SM, Martukanitz RP, DebRoy T (2008) A convective heat-transfer model for partial and full penetration keyhole mode laser welding of a structural steel. Metall Mater Trans A Phys Metall Mater Sci 39:98-112. https://doi.org/10.1007/s11661-0079400-6

28. Piekarska W, Kubiak M (2013) Modeling of thermal phenomena in single laser beam and laser-arc hybrid welding processes using projection method. Appl Math Model 37:2051-2062. https://doi. org/10.1016/j.apm.2012.04.052

29. Xu P-Q, Bao C-M, Lu F-G, Ma CW, He JP, Cui HC, Yang SL (2011) Numerical simulation of laser-tungsten inert arc deep penetration welding between WC-Co cemented carbide and invar alloys. Int J Adv Manuf Technol 53:1049-1062. https://doi.org/10.1007/ s00170-010-2898-6

30. Abderrazak K, Bannour S, Mhiri H, Lepalec G, Autric M (2009) Numerical and experimental study of molten pool formation during continuous laser welding of AZ91 magnesium alloy. Comput Mater Sci 44:858-866. https://doi.org/10.1016/j.commatsci.2008.06.002

31. Faraji AH, Goodarzi M, Seyedein SH, Barbieri G, Maletta C (2015) Numerical modeling of heat transfer and fluid flow in hybrid laserTIG welding of aluminum alloy AA6082. Int J Adv Manuf Technol 77:2067-2082. https://doi.org/10.1007/s00170-014-6589-6

32. Faraji AH, Moradi M, Goodarzi M, Colucci P, Maletta C (2017) An investigation on capability of hybrid Nd:YAG laser-TIG welding technology for AA2198 Al-Li alloy. Opt Lasers Eng 96:1-6. https://doi.org/10.1016/j.optlaseng.2017.04.004

33. Faraji AH, Goodarzi M, Seyedein SH, Maletta C (2016) Effects of welding parameters on weld pool characteristics and shape in hybrid laser-TIG welding of AA6082 aluminum alloy: numerical and experimental studies. Weld World 60:137-151. https://doi.org/10. 1007/s40194-015-0278-4
34. Akbari M, Saedodin S, Toghraie D, Shoja-Razavi R, Kowsari F (2014) Experimental and numerical investigation of temperature distribution and melt pool geometry during pulsed laser welding of Ti6Al4V alloy. Opt Laser Technol 59:52-59. https://doi.org/ 10.1016/j.optlastec.2013.12.009

35. Rai R, Elmer JW, Palmer TA, Debroy T (2007) Heat transfer and fluid flow during keyhole mode laser welding of tantalum, Ti-6Al4V, 304L stainless steel and vanadium. J Phys D Appl Phys 40: 5753-5766. https://doi.org/10.1088/0022-3727/40/18/037

36. Raghavan N, Dehoff R, Pannala S, Simunovic S, Kirka M, Turner J, Carlson N, Babu SS (2016) Numerical modeling of heat-transfer and the influence of process parameters on tailoring the grain morphology of IN718 in electron beam additive manufacturing. Acta Mater 112:303-314. https://doi.org/10.1016/j.actamat.2016.03.063

37. Nie P, Ojo OA, Li Z (2014) Numerical modeling of microstructure evolution during laser additive manufacturing of a nickel-based superalloy. Acta Mater 77:85-95. https://doi.org/10.1016/j. actamat.2014.05.039

38. Patankar SV (1980) Numerical heat transfer and fluid flow. Taylor \& Francis, Boca Raton

39. Chen YB, Lei ZL, Li LQ, Wu L (2006) Experimental study on welding characteristics of $\mathrm{CO}^{2}$ laser TIG hybrid welding process. Sci Technol Weld Join 11:403-411. https://doi.org/10.1179/ $174329306 \times 129535$

40. Zhou J, Tsai HL (2008) Modeling of transport phenomena in hybrid laser-MIG keyhole welding. Int J Heat Mass Transf 51:4353-4366. https://doi.org/10.1016/j.ijheatmasstransfer.2008.02.011

41. Wang J, Pan Z, Ma Y, Lu Y, Shen C, Cuiuri D, Li H (2018) Characterization of wire arc additively manufactured titanium aluminide functionally graded material: microstructure, mechanical properties and oxidation behaviour. Mater Sci Eng A 734:110-119. https://doi.org/10.1016/j.msea.2018.07.097

Publisher's note Springer Nature remains neutral with regard to jurisdictional claims in published maps and institutional affiliations. 